\title{
EVOLUÇÃO DO PERFIL DA PROVA DE FÍSICA DO VESTIBULAR DA \\ UFMG
}

\author{
EVOLUTION OF THE PROFILE OF THE PHYSICS TEST FOR ACCESS TO THE \\ UFMG
}

\author{
Simone A. Fernandes ${ }^{1}$ \\ José Guilherme Moreira²
}

\section{RESUMO}

Até apresentar o perfil atual, as provas de Física do vestibular da UFMG passaram por várias mudanças devido ao contexto educacional da época. Neste trabalho, apresentamos como as formas de abordagem dos conteúdos de Física evoluíram desde a implementação do vestibular, em 1970, até os dias atuais. Para isso, analisamos questões dessas provas e entrevistamos alguns professores que fizeram parte das equipes de elaboração das provas. Percebemos que várias formas de abordagem do conteúdo de Física defendidas hoje já estavam presentes nas questões da década de oitenta, mostrando que o perfil atual das provas é herança da postura assumida pela equipe daquela década.

Palavras-chave: ensino de física; provas de física do vestibular.

\begin{abstract}
The physics exams for access to the UFMG had passed for some changes until presenting the current profile, according to the educational context of the epoch. In this work, we present how the physics content approach have been evolved since the access exam implementation (1970) until today. For this, we analyzed some questions of these exams and we performed some interviews with professors from the elaboration exam team. We perceived that several tendencies in Physics exams were present since 80's. This means that the current shape in the Exams is inheritance of the 80’s professors Exam Team thought.
\end{abstract}

Keywords: physics teaching; physics exams.

\footnotetext{
${ }^{1}$ Departamento de Física - UFMG - sifisica@yahoo.com.br

${ }^{2}$ Departamento de Física - UFMG - jmoreira@fisica.ufmg.br
} 


\section{1 - INTRODUÇÃO}

As críticas acerca dos vestibulares são muitas, porém existem poucos trabalhos abordando o tema e aqueles encontrados centram suas discussões principalmente na sua repercussão social (VASCONCELLOS, 2000a; 2000b; NETO, 1995). Discussões acerca desse processo seletivo são importantes, pois, os vestibulares interferem nas expectativas dos pais e alunos, no trabalho dos educadores, na mídia, promovem um mercado de produtos e serviços voltados para seus concursos e são citados como um dos fatores de distorção da prática pedagógica desenvolvida na escola (VASCONCELLOS, 2000, p.87).

Além disso, acreditamos que as provas dos vestibulares das Instituições de Ensino Superior (IES), em especial as que têm cursos de licenciatura, devem representar a concepção de ensino dessa Instituição. Essa concepção de ensino reflete na formação que está sendo dada aos futuros profissionais do Ensino Médio e, portanto, é importante que os processos seletivos das IES estejam preocupados com a sua repercussão no processo educacional.

Para investigar esse ponto, foi desenvolvida uma dissertação de mestrado que tinha como objetivo investigar as formas de abordagem do conteúdo de Física em provas de vestibulares de algumas Instituições de Ensino Superior, entre elas, a Universidade Federal de Minas Gerais (FERNANDES, 2004). A motivação para o trabalho aqui apresentado surgiu durante essa investigação.

Notamos que, desde 1970 até assumir a identidade atual, as provas de Física do vestibular UFMG sofreram várias mudanças e influências. Diante disso, e de posse das provas desde a década de 70 até o último vestibular, surgiu o desejo de se apresentar um histórico dessas provas ao longo das últimas décadas, enfocando os tipos de abordagens presentes, as influências que contribuíram para mudanças significativas - seja por parte das reformas educacionais ou tendências educacionais ocorridas ao longo dos anos - e a postura assumida pelas equipes em relação ao Ensino Médio.

Assim, o objetivo deste trabalho é mostrar como as provas de Física do vestibular da UFMG, em especial as da $1^{\text {a }}$ etapa, evoluíram até apresentarem o perfil atual. 


\section{2 - O VESTIBULAR UFMG}

O processo seletivo da UFMG passou por algumas mudanças ao longo das décadas. Essa forma de seleção centralizada foi introduzida em 1970. Antes disso, cada Escola - Direito, Engenharia, Medicina etc. - era responsável pela seleção dos alunos para seus cursos. De 1970 a 1977, o processo foi único, ou seja, provas iguais para todos os candidatos, independente da opção de curso. A partir de 1978, foram introduzidas duas etapas - a primeira tem esse caráter único e serve como seleção para a segunda etapa que consiste de provas abertas específicas para as diversas áreas.

Atualmente, o processo seletivo ainda é composto por duas etapas. A primeira delas, formada por questões de múltipla-escolha, tem por objetivo “avaliar $a$ escolaridade básica do candidato” (UFMG, 2005). Essa etapa preocupa-se, em avaliar habilidades de interpretação, compreensão e aplicação de conceitos básicos inerentes a cada área de conhecimento compreendida nos programas da Educação Básica. A segunda etapa tem por objetivo avaliar mais profundamente o domínio dos candidatos em relação àqueles conhecimentos pertinentes ao curso pretendido. Essa etapa compreende, assim, questões discursivas que exigem raciocínio mais elaborado (DALBEN, 1999, p.9).

Dentro do espírito relatado, a prova de Física de Primeira Etapa, de acordo com o Programa apresentado no Manual do Candidato de 2006, tem como objetivo

[...] avaliar o candidato quanto ao conhecimento e à compreensão de conceitos fundamentais da Física e à aplicação desses conceitos na interpretação de fenômenos naturais, de fatos da vida cotidiana, de experimentos simples e de aplicações tecnológicas. Nessa etapa, a ênfase é mais conceitual e qualitativa e menos matemática e quantitativa [UFMG, 2005].

\section{3 - METODOLOGIA}

Para este trabalho, tivemos conversas com vários professores que fizeram parte da Equipe de Elaboração das Provas de Física do vestibular da UFMG ao longo das décadas de 60 a 90. Conversamos com os professores Jésus de Oliveira, que participou dessa equipe por mais de três décadas (1960 - 1994) e durante grande parte desse tempo desempenhou o papel de coordenador da mesma; Árjuna Panzera, membro da equipe desde o final da década de 80 até meados da década 90; Antônio Máximo, que participou da equipe desde a década de 80 até 1995; e, por último, contamos com a participação da professora Beatriz Alvarenga que esteve ligada, intermitentemente, à elaboração das provas de Física desde a década de 50 até o início 
da década de 90. As conversas com os professores Àrjuna e Jésus foram realizadas em março de 2005 no Departamento de Física da UFMG. Os encontros com os professores Antônio Máximo e Beatriz Alvarenga aconteceram em seus escritórios nesse mesmo período.

Para as conversas com os professores utilizamos entrevista não estruturada em que os tópicos a serem cobertos estavam pré-determinados em um roteiro, porém, as questões emergiam durante a conversa e os professores tinham maior liberdade para a narrativa. Posteriormente, as conversas foram transcritas e a partir do vários depoimentos estruturamos este relato histórico.

A próxima seção apresenta um resumo dessas conversas com pontos interessantes na história das provas de Física do vestibular da UFMG. Salientamos suas características, abordagens, relação com o Ensino Médio - antigo Segundo Grau -, preocupações enfrentadas pelas equipes, influências que contribuíram para que ao longo das décadas as provas sofressem mudanças e adequações, até alcançarem o perfil que hoje conhecemos.

Na seção seguinte, destacamos uma seleção de questões mostrando como alguns tópicos do conteúdo de Física eram abordados e como são abordados atualmente. As questões apresentadas são categorizadas levando-se em conta a presença ou não de abordagens contextualizadas e interdisciplinares; o nível de exigência de conhecimentos e habilidades matemáticas; e, ainda, as formas de valorização do conhecimento e da compreensão de conceitos físicos (FERNANDES, 2004). Essa categorização foi proposta levando-se em conta as orientações das DCNEM - Diretrizes Curriculares Nacionais para o Ensino Médio (BRASIL, 1998) e dos PCN - Parâmetros Curriculares Nacionais (BRASIL, 1999) que foram elaborados após a promulgação da nova $\mathrm{LDB}^{3}$.

Por fim, concluindo o trabalho, fazemos uma breve discussão a respeito da influência da reforma educacional nas formas de abordagens apresentadas pelas questões de Física do vestibular da UFMG.

\footnotetext{
${ }^{3}$ O processo de reforma educacional teve início em 1996 com a promulgação da nova Lei de Diretrizes e Bases da Educação Nacional (LDB) e, com relação ao Ensino Médio, foi detalhado nas DCNEM e nos PCN.
} 


\section{4-A ELABORAÇÃo DAS PROVAS DE FÍSICA DO VESTIBULAR DA UFMG NA VOZ DOS ATORES ENVOLVIDOS}

Em 1958 quando o professor Jésus prestou vestibular para a Faculdade de Filosofia ${ }^{4}$, a prova de Física era composta de duas partes, a primeira parte escrita e a segunda parte oral.

"[...] tinha uma parte teórica de redação e tinha uma parte de prova oral [...] tinha uma banca examinadora e o resto da turma assistindo [...]."

Professor Jésus de Oliveira.

Esses processos seletivos enfrentaram vários problemas, entre eles o excedente de alunos. Como, naquela época, o exame de vestibular era eminentemente avaliativo, bastava que o aluno atingisse uma nota mínima para ser aprovado pela Universidade. Assim, em vários cursos, o número de alunos aprovados acabava sendo maior que o número de vagas oferecidas. Isso acabava gerando um excedente de alunos e, dessa forma, vários desses alunos não conseguiam ingressar na Universidade. Em outros cursos, como no curso de Física, ocorria o contrário - o número de vagas disponíveis era maior que o número de candidatos aprovados.

“[...] o vestibular quando eu fiz era do nível mesmo dos colégios daquela época, tinha uma prova escrita e uma prova oral. Agora, tinha uma média mínima para passar [...] quando eu entrei no primeiro ano de Física nós éramos cinco alunos diante de vinte vagas ou trinta."

Professor Jésus de Oliveira.

Até a década de 70, a inexistência de um vestibular único contribuía para a distorção da Física trabalhada em sala de aula e dificultava o trabalho dos professores no Ensino Secundário, como era chamado. Como a Universidade compreendia várias Escolas - de Medicina, de Direito, de Engenharia, entre outras -, cada uma delas era responsável pelo processo seletivo para seus cursos tendo, portanto, autonomia para elaborarem suas provas. Essa autonomia das Escolas representava um verdadeiro transtorno para o trabalho desenvolvido pelos professores de Física, principalmente nos cursos Científico e Clássico, que eram basicamente cursos preparatórios para o Ensino Superior.

Dessa forma, as provas de Física não apresentavam um perfil definido. Como os professores eram cobrados pelos alunos a trabalharem a Física que era exigida no vestibular, era difícil atender a alunos com perspectivas diferentes. Isso era problema mesmo para aqueles professores que lecionavam somente no curso Científico, pois a

\footnotetext{
${ }^{4}$ Naquela época o curso de Física pertencia à Faculdade de Filosofia.
} 
prova de Física da Escola de Medicina apresentava uma abordagem totalmente diferente da prova da Escola de Engenharia, por exemplo.

Além disso, as Escolas elaboravam suas provas com o objetivo de medir os conhecimentos considerados pré-requisitos para seus cursos. Assim, nem sempre elas abordavam um conhecimento significativo de Física. Por outro lado, algumas Escolas se espelhavam em outros vestibulares, o que elevava o nível de dificuldade das provas e era mais uma influência negativa do processo seletivo no ensino de Física da escola média.

"Qual era o grande problema que a gente tinha relacionado com a Física também? Os vestibulares
eram feitos isoladamente, por exemplo, para Medicina tinha prova de Física e a prova era feita lá
dentro da Medicina por pessoas da Escola de Medicina. Você pode imaginar o quê que saía né! O
quê que era uma prova de física preparada por aquele pessoal lá [...] você pode imaginar a
influência que tinha uma prova de Física da Escola de Medicina no chamado Ensino Médio. A Escola
de Engenharia tinha Física no vestibular dela e a prova era preparada lá dentro da Escola de
Engenharia, pelo pessoal da Engenharia. Então, como eram pessoas mais bem preparadas em Física,
tinham conhecimentos gerais, saía uma prova um pouco melhor, mas, mesmo assim, com
característica muito formais, muito matemáticas, cobrando coisas assim, que a gente que tinha uma
formação em Física achava que não era uma boa prova e você imagina que isso tinha influência
também. Além da orientação ser mais ou menos assim, eles têm um negócio de querer colocar assim
uma marca do ITA que é um negócio de nível altíssimo, de problema de quebra-cabeça, mas era mais
ou menos uma coisa assim."

Professor Antônio Máximo.

Por último, as abordagens apresentadas na provas muitas vezes não correspondiam ao que o professor do Ensino Médio julgava ser um bom ensino de Física, assim, “era um verdadeiro pesadelo para quem queria dar uma boa Física no Ensino Médio” (Professor Antônio Máximo, 2004).

Essas situações só vieram a mudar a partir da Reforma Universitária de 1968. Com a implantação do vestibular único em 1970, as provas de Física passaram a ser preparadas no Departamento de Física, o que contribuiu para que ela assumisse um perfil, uma identidade. De acordo com o depoimento do Professor Antônio Máximo essa novidade foi recebida com grande alívio pelos professores do Ensino Médio.

"Quando surgiu o vestibular unificado, aí o quê que era? As provas eram preparadas dentro do departamento de Física da UFMG. Então, era uma prova com conceitos, idéias, uma Física sadia que a gente achava. Então para nós aquilo foi um alívio afinal né, porque a gente podia então lecionar nas nossas escolas de Ensino Médio a Física que ia ser cobrada depois no vestibular. Então a pressão caiu demais."

Professor Antônio Máximo.

Percebe-se, pelos depoimentos apresentados pelo Professor Antônio Máximo, que o Ensino Secundário - nos cursos Científico e Clássico - estava declaradamente em função do vestibular. Devido a essa relação natural qualquer mudança no processo 
seletivo refletia diretamente no trabalho desenvolvido pelos professores de Física em sala de aula. Segundo esse professor, a adoção do vestibular único, a princípio, influenciou de forma positiva o Ensino Secundário, porém, com o tempo percebeu-se que as mudanças no ensino de Física não foram tão significativas quanto se esperava.

“Num primeiro momento a gente achava que o vestibular único seria a salvação [...] A primeira coisa que eu notei é o seguinte: alguns anos depois do vestibular único eu comecei a descobrir que era muito bom ter esse modelo, mas não era tão bom assim quanto eu pensava não. Você não consegue influenciar tanta gente assim como você está pensando com o vestibular, infelizmente. Então a gente começou a perceber que tinha um número grande de escolas, de cursos, etc., que ensinavam Física no Ensino Médio que realmente eles se espelhavam ali no vestibular da federal, passavam a ensinar um curso de Física melhor, mais conceitual, mas tinha pessoas que tinham uma formação de Física clássica, tradicional, que não mudava de jeito nenhum. Então foi assim com muita tristeza que eu descobri que a arma que a gente tem em mãos aí, que é o vestibular, ela é uma arma poderosa, muito boa, mas ela não é assim cem por cento, está longe de ser cem por cento.”

Professor Antônio Máximo.

Algumas pesquisas realizadas por uma editora de livros didáticos, às quais o professor tinha acesso, mostravam que muitas escolas do Ensino Médio mantiveram suas práticas pedagógicas tradicionais, pautadas em um ensino de Física tradicional, refém do formalismo matemático e distante da conceituação.

"Muitas escolas aí - eu tenho pesquisas aí, porque a minha editora fazia pesquisas em escolas no Brasil inteiro ... os professores respondiam os questionários, então eu tinha uma visão de como que eles estão dando Física na escola tal, na cidade tal, na região tal, falando de Minas - então, tinha muita gente que não tinha nem se abalado, continuava a dar aquela Física clássica, tradicional. A pessoa não mudava! Não mudava simplesmente porque ela não tem condições de mudar, porque a Física que ele conhece é aquela, né? [...] Então, esse vestibular único feito pelo departamento mudou o Ensino de Física para melhor, isso eu não tenho dúvida nenhuma, mas ele mudou quem tinha condições de mudar, quem não tinha simplesmente não mudou, continuou a dar aqueles cursos de Física tradicionais, horríveis [...].”

Professor Antônio Máximo.

Além disso, as provas de outras IES locais tinham outras formas de abordagem, o que era mais um entrave para um trabalho diferenciado no Ensino Médio.

"Você ia lecionar uma Física mais conceitual, uma Física que você achava que era mais
interessante, menos formal, etc., e o aluno começava a cobrar: Ah! Mais isso aí é na Federal, na
Católica, por exemplo, não é!”
"Eu cheguei a ter que fazer cursos separados na instituição onde eu trabalhava. Dar duas Físicas
diferentes. Olha bem, era um retrocesso!”

Professor Antônio Máximo.

Apesar de o vestibular único ter representado um avanço na forma de selecionar candidatos, ele logo se mostrou inadequado uma vez que a mesma prova era aplicada a candidatos com interesses distintos. Esse foi um dos problemas que 
incomodou os membros da equipe e contribuiu para que esse modelo de seleção passasse a ser questionado.

“A primeira coisa que aconteceu com o vestibular único, foi que ele se mostrou inadequado, porque você tinha lá milhares de estudantes destinados às mais diversas áreas e na verdade você aplicava a mesma prova. Isso não precisa ser nenhum especialista em ensino para você ver que isso não funcionava, a prova que você aplica para testar ou cobrar os conhecimentos básicos na escola de engenharia não é a mesma Física que você iria cobrar e exigir de um aluno que vai fazer Direito, por exemplo. Está certo? [...] Como dizia o Jésus: se você jogar uma moeda para cima para tirar um sorteio dá a mesma coisa, não há diferença. Foi aí que nasceu então a briga que durou muito tempo para se fazer o vestibular por áreas. Essa briga surgiu daí.”

Professor Antônio Máximo.

Outro problema que trouxe algumas mudanças para as provas, foi a adoção da técnica de múltipla-escolha, no entanto, a equipe sempre esteve preocupada com a forma de elaboração das questões.

“Quando começou a moda da múltipla-escolha então, a gente começou a fazer alterações [...] nesse tempo então, começou primeiro uma prova só, uma prova de múltipla-escolha e, naturalmente, conforme nós sabemos essas provas de múltipla-escolha se você não faz bem feita, às vezes, elas tornam-se questão de adivinhação."

Professora Beatriz Alvarenga.

A partir desses problemas, começou a tentativa de se estabelecer o vestibular por áreas, sistema adotado até hoje na UFMG. Os próprios professores da Equipe de Elaboração se envolveram nessa tentativa que, segundo o professor Antônio Máximo, durou muito tempo.

"A Beatriz foi uma das que levantou essa bandeira de mudar isso porque não podia continuar daquele jeito, você aplicando a mesma prova que você aplica a um grupo aplicando a outro totalmente diferente [...]."

Professor Antônio Máximo.

"Quando nós começamos a trabalhar no vestibular eu me bati muito pelas duas etapas porque eu achava que havia uma necessidade de primeiro fazer questões que a gente achava que era de conhecimento geral, a Física para todos. Eu sempre fui favorável a essa Física para todos."

Professora Beatriz Alvarenga.

Quanto à influência no Ensino Médio, as equipes sempre tiveram claro o papel do vestibular e da prova de Física nesse processo seletivo.

“Eu sempre defendia para a comissão que o vestibular tinha duas funções fundamentais, a de barreira - de seleção - [...] e a de servir de espelho para o Ensino Médio [...] A idéia de o quê que a gente estava querendo que se ensinasse... dar algum reflexo para o Ensino Médio. Isso era ponto que era levado em conta na elaboração da prova."

Professor Jésus de Oliveira

Desde o início sempre houve reuniões entre os membros da equipe e os professores do Ensino Médio e dos cursinhos. Nessas reuniões, que acontecem até hoje, a prova do vestibular anterior era discutida e alguns índices estatísticos - como o 
índice de acerto, de discriminação de cada questão, entre outros -, eram apresentados e discutidos.

“A Beatriz e Antônio Máximo conversavam muito com colégios. Tinha uma reunião geral - que ainda tem até hoje - da comissão com professores e eles faziam as críticas e tal [...].”

Professor Jésus de Oliveira

"A gente sempre analisou a prova de um ano para o outro, sempre tem aquela reunião com professores de Ensino Médio e de cursinhos que vêm aí e que a gente discute as provas.”

Professor Árjuna

Com relação à maneira como o conteúdo deveria ser abordado, sempre houve uma preocupação em manter um nível semelhante de um ano para outro e a distribuição dos conteúdos na prova deveria estar de acordo com essa distribuição no programa, tomando-se o cuidado de não privilegiar um tema em detrimento a outro. Além disso, as questões privilegiavam uma abordagem em que “dependesse o mínimo possível de memória, da memorização” (Professor Jésus, 2004).

“[...] sempre teve essa preocupação de dividir e pegar toda a Física. Então se eram quinze questões, assim, 30\%, 40\% , sempre foi essa proporção. Teve sempre essa preocupação de dividir, de ser proporcional à proporcionalidade do programa de cada conteúdo da Física. Sempre a Beatriz e o Antônio Máximo estavam no meio e o espírito de Ensino de Física deles era contextualizado, a Física não matematizada, então são questões mais qualitativas, semi-quantitativas e mais contextualizadas ou ligadas a experimentação. Então sempre foi uma constante na elaboração das questões tentar elaborar segundo essa ótica aí”.

Professor Árjuna

“[...] a gente sempre está preocupado em o quê que você está medindo quando faz uma prova. Isso não é muito claro não, mas é inerente em toda medida que você faz."

Professor Jésus de Oliveira

Enfim, foi nesse contexto de mudanças e adequações em busca de uma prova que pudesse avaliar o espectro mais amplo possível de candidatos, que se insere a história das provas de Física do vestibular da UFMG.

A sessão a seguir apresenta algumas questões das provas de primeira etapa que ilustram influências, tendências, mudanças nas formas de abordagem e que contribuíram para que a prova de Física da UFMG assumisse o perfil que tem hoje.

\section{5 - PERFIL DAS PROVAS DE FÍSICA NA DÉCADA DE 70}

Procuraremos mostrar, como forma de ilustração das mudanças ocorridas nas questões da prova de Física do vestibular da UFMG, algumas questões de Física que tratam o mesmo conteúdo e suas formas de abordagem ao longo das décadas. Antes, 
porém, destacaremos algumas características interessantes apresentadas pelas provas da década de 70, depois da adoção do processo de seleção unificado.

Com a implementação do vestibular único, as provas de Física passaram a ser elaboradas por professores do Departamento de Física, o que lhes deu um novo perfil quanto às formas de abordagem dos conteúdos. Mesmo assim, no início as provas eram longas - em 1970 foram 75 questões e, de 1971 a 1977, 36 questões - e compostas por várias questões referentes a uma única situação. Assim, era possível encontrar 9 questões, ou seja, 1/4 da prova, referentes a um único problema, como mostrado no Quadro 1.

“No princípio, quando nós começamos a fazer as provas, nós fazíamos as provas daquela maneira mesmo, com problemões. Às vezes em uma prova eram cinco problemas que caíam e pronto, as questões da prova eram essas."

Professora Beatriz Alvarenga

Além de serem muito extensas, as provas do início da década de 70 se enquadravam em um perfil mais acadêmico, ou seja, as questões eram apresentadas a partir de uma abordagem que valorizava alguns tópicos como algarismos significativos, ordem de grandeza, medidas e erros em medidas, que eram conteúdos de cunho mais acadêmico. Questões desse tipo (Quadros 2 e 3), comuns no início dessa década, exigiam um conhecimento matemático mais ligado à análise de dados experimentais, envolvendo pouco conhecimento de conceitos físicos.

A valorização desses conteúdos se justificava, segundo o professor Jésus, pela influência do PSSC $^{5}$ que, na época, gerou uma tendência de valorização do trabalho experimental e pela idéia de que a Física experimental era indispensável no Brasil.

“Naquela época tinha-se a idéia de que a medida era uma coisa indispensável no Brasil porque todo mundo falava assim: o brasileiro está ainda naquele estilo grego que o trabalho com as mãos deixa para os escravos, ele deve trabalhar com a cabeça. Então era uma espécie de reação a esse tipo de coisa."

Professor Jésus de Oliveira

\footnotetext{
${ }^{5}$ PHYSICAL SCIENCE STUDY COMMITTEE foi um projeto financiado pelo governo americano na década de 60 (PSSC, 1963).
} 
Quadro 1: Questões 18 a 23 / vestibular 1975

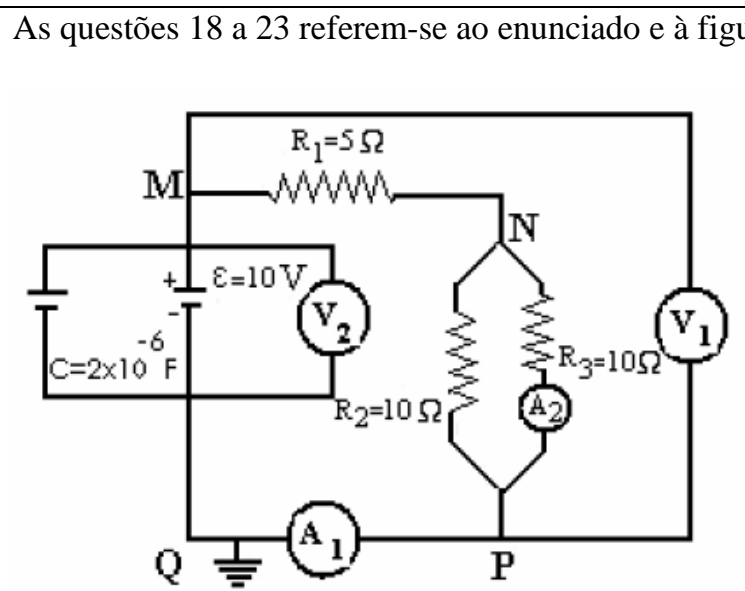

Considere o diagrama ao lado no qual C é um capacitor, $A_{1} A_{2}$ são amperímetros (de resistências desprezíveis) e $V_{1}$ e $V_{2}$ são voltímetros (de resistências praticamente infinitas). A resistência interna da bateria é desprezível.

\section{QUESTÃO No 18}

A resistência total do circuito é:
A) $10 \Omega$
B) $25 \Omega$
C) $4,0 \Omega$
D) $5,2 \Omega$
E) $2,5 \Omega$

\section{QUESTÃO No 19}

A corrente fornecida pela bateria é:
A) $1,0 \mathrm{~A}$
B) $0,4 \mathrm{~A}$
C) $2,5 \mathrm{~A}$
D) $1,9 \mathrm{~A}$
E) $4,0 \mathrm{~A}$

\section{QUESTÃO No 20}

Indicar a afirmação ERRADA:

A) As leituras de $V_{1}$ e $V_{2}$ são iguais.

B) A leitura de $V_{1}$ é $10 \mathrm{~V}$.

C) A diferença de potencial entre $\mathrm{M}$ e $\mathrm{N}$ é igual à diferença de potencial entre $\mathrm{N}$ e $\mathrm{P}$.

D) o potencial no ponto P é $10 \mathrm{~V}$.

E) Retirando uma das resistências de $10 \Omega$ do circuito a leitura de $V_{1}$ continua a mesma de antes.

\section{QUESTÃO No 21}

Indicar a afirmação ERRADA:

A) A corrente que passa por $\mathrm{R}_{1}$ é lida em $\mathrm{A}_{1}$

B) A leitura de $\mathrm{A}_{2}$ é 0,5 A.

C) A corrente que entra em $M$ é a mesma que sai em $P$.

D) Substituindo $V_{1}$ por uma resistência de $10 \Omega$ a leitura de $A_{2}$ aumenta.

E) Retirando uma das resistências de $R_{3}$ do circuito a leitura de $A_{1}$ diminui.

\section{QUESTÃO Nº 22}

Se a resistência interna da bateria não fosse desprezível, poderíamos afirmar:
A) A leitura de $V_{2}$ seria de $10 \mathrm{~V}$.
B) A leitura de $V_{1}$ seria menor que a de $V_{2}$.
C) A leitura de $V_{1}$ seria menor do que $10 \mathrm{~V}$.
D) A leitura de $V_{1}$ seria maior do que a de $V_{2}$.
E) A f.e.m da bateria seria menor do que $10 \mathrm{~V}$.

QUESTÃO No 23

Sejam $P_{1}, P_{2}$ e $P_{3}$ as potências dissipadas respectivamente nas resistências $R_{1}, R_{2}$ e $R_{3}$ e i a corrente fornecida pela bateria. A afirmativa CORRETA é:
A) $\varepsilon \mathrm{i}<\mathrm{P}_{1}+\mathrm{P}_{2}+\mathrm{P}_{3}$
B) $\mathrm{P}_{1}>\mathrm{P}_{2}$
C) $\frac{1}{P_{1}}=\frac{1}{P_{2}}+\frac{1}{P_{3}}$
D) $\varepsilon \mathrm{i}=\mathrm{P}_{1}+\frac{P_{2} x P_{3}}{P_{2}+P_{3}}$
E) $\varepsilon \mathrm{i}=\left(\mathrm{R}_{1}+\mathrm{R}_{2}+\mathrm{R}_{3}\right) \mathrm{i}^{2}$ 
Quadro 2 - Questões 1 e 2 / vestibular 1970

QUESTÃO N 1:

Um velocímetro impreciso de um automóvel marca $60 \mathrm{~km} / \mathrm{h}$ quando o valor correto é $65 \mathrm{~km} / \mathrm{h}$. O êrro percentual cometido na leitura do velocímetro é:
(A) $6,0 \%$
(B) $6,5 \%$
(C) $7,7 \%$
(D) $8,3 \%$
(E) $9,2 \%$

QUESTÃO N²:

Dois comprimentos a e b foram medidos com uma régua, cuja incerteza é de $0,1 \mathrm{~cm}$. Os valores obtidos foram $\mathrm{a}=50,0 \mathrm{~cm}$ e $\mathrm{b}=55,0 \mathrm{~cm}$. A incerteza na diferença $\mathrm{b}-\mathrm{a}$ será de:
(A) $0,2 \mathrm{~cm}$
(B) $5,5 \mathrm{~cm}$
(C) 0
(D) $5 \mathrm{~cm}$
(E) $0,1 \mathrm{~cm}$

Quadro 3 - Questão 30 / vestibular 1973

INSTRUÇÃO: Nas questões de números 27 a 32 apresentam-se três afirmativas, cada uma das quais pode ser certa ou errada. Leia-as com atenção e responda:
A) Se apenas uma afirmativa é certa
B) Se apenas I e II são corretas
C) Se todas as afirmativas são erradas
D) Se apenas I e III são certas
E) Se todas as afirmativas são certas

QUESTÃO 30:

Os valores dados abaixo representam uma série de medidas de comprimento, tomada com instrumentos diferentes.
1) $(516,0 \pm 0,5) \mathrm{km}$
2) $(0,0240 \pm 0,0006) \times 10^{-6} \mathrm{~m}$
3) $(36,00 \pm 0,03) \mathrm{m}$
4) $(1,50 \pm 0,03) \times 10^{3} \mathrm{~m}$
5) $(3909 \pm 4) \mathrm{m}$

I - As medidas 3) e 4) foram obtidas com a mesma precisão.

II - Se as medidas representam comprimentos adjacentes, o comprimento total será de 521,445 km.

III - A medida mais precisa é a 2).

Além disso, percebe-se que havia muita valorização de questões em que o aluno deveria reconhecer a equação matemática relacionada ao problema apresentado e questões envolvendo interpretação gráfica. Em uma mesma prova é possível encontrar várias questões envolvendo gráficos. Em algumas delas o aluno deveria interpretá-los relacionando as grandezas ali envolvidas e outras deveriam ser resolvidas a partir de um único gráfico apresentado. No Quadro 4, apresentamos um exemplo de questão que mostra uma situação a partir da qual o aluno deve reconhecer o gráfico que melhor a representa.

Quadro 4 - Questão 01 / vestibular 1971

Um cientista descobriu, por meio de experiências realizada em seu laboratório, que uma grandeza X era diretamente proporcional à raiz quadrada de uma outra grandeza Y. Entre as anotações do cientista foram encontrados alguns gráficos, que reproduzimos abaixo. Assinale aquele que representa a descoberta acima citada.
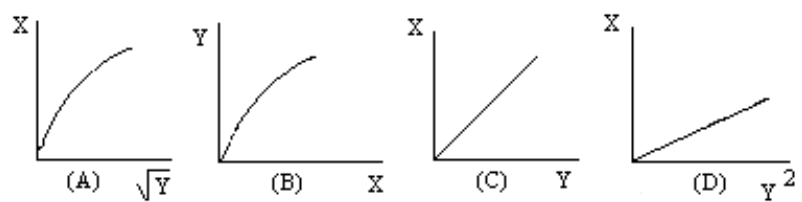

(E) Nenhum dêstes. 
Ainda na década de 70, eram muito comuns questões teóricas, que exigiam dos alunos o conhecimento do enunciado de leis Físicas ou de nomes de cientistas que contribuíram para o desenvolvimento dessa ciência, como mostrado no Quadro 5.

Quadro 5 - Questão 01 / vestibular 1978

\section{QUESTÃO N 1}

Que alternativa contém apenas nomes de pessoas que contribuíras significativamente para o desenvolvimento da Física?

A) Coulomb, Galileu, Newton, Joule, Oersted.

B) Lineu, Galileu, Dante, Einstein, Goethe.

C) Arquimedes, Pascal, Galeno, Pasteur, Maquiavel.

D) Planck, Einstein, Dostoiewsky, Sabin, Mendel.

E) Galileu, Mendeleiev, Fermi, Voltaire, Proust.

$[\ldots]$

Algumas questões apresentavam uma afirmação seguida de uma justificativa a ser julgada como falsa ou verdadeira pelo aluno, como no Quadro 6. Essa forma de propor a questão era muito comum em todas as provas dessa época.

Quadro 6 - Questão 11 / vestibular 1973

INSTRUÇÃO: Nas questões de 7 a 14 são feitas duas afirmativas ligadas pela palavra PORQUE. Responda:

A) Se a $1^{\underline{a}}$ é uma afirmativa certa e a $2^{\underline{a}}$ é uma afirmativa errada.

B) Se a $1^{\underline{a}}$ e a $2^{\underline{a}}$ são afirmativas erradas.

C) Se as duas afirmativas são certas e a $2^{\underline{a}}$ é causa da $1^{\underline{a}}$.

D) Se a $1^{\underline{a}}$ é uma afirmativa errada e a $2^{\underline{a}}$ é uma afirmativa certa.

E) Se as duas afirmativas são certas mas a $2^{\underline{a}}$ não é causa da $1^{\underline{a}}$.

[...]

QUESTÃO 11: "O calor de vaporização de uma substância é a quantidade de calor necessária para mudar $1,00 \mathrm{~kg}$ da substância, do estado líquido ao estado de vapor na temperatura de vaporização" PORQUE "a temperatura de uma substância, durante o processo de mudança de fase de líquido a vapor, varia $[\ldots]$ linearmente coma quantidade de calor fornecido."

Outras questões traziam várias afirmativas para que o aluno julgasse, dentre elas, a afirmativa falsa ou, às vezes, a afirmativa verdadeira. Um exemplo é apresentado no Quadro 7.

Quadro 7 - Questão 35 / vestibular 1976

Qual a afirmativa ERRADA?

Dois diapasões entram em ressonância se:

A) suas freqüências forem iguais.

B) seus períodos forem iguais.

C) suas amplitudes forem iguais.

D) a freqüência de um for um múltiplo da freqüência do outro.

E) o período de um for sub-múltiplo do período de outro. 
Outra coisa que podemos destacar é que, logo no início da década de 70, questões referentes à Física Moderna já estavam presentes nas provas de vestibular. Como mostra o Quadro 8, a abordagem dessas questões se dava, também, de forma teórica, a partir de um texto apresentado aos candidatos.

“As questões de Física moderna era um texto do qual se tiravam as questões. Mesmo que a pessoa não soubesse Física Moderna ele poderia tirar informações dos textos. Era um texto onde você colocava um assunto e as questões eram sobre aquele assunto. Mesmo que a pessoa não soubesse, se ela lesse ali tinha informações básicas para fazer a questão.”

Professor Árjuna

Mesmo algumas questões que não tratavam de Física Moderna costumavam ter um enunciado um pouco mais longo, mais elaborado, trazendo algumas informações. Esse modo de apresentar a questão se devia à influência da professora Beatriz Alvarenga, que sempre procurava relacionar o conteúdo físico abordado a algumas situações.

"Eu tinha uma tendência de às vezes contar uma historinha para poder fazer a questão em torno daquilo [...] eu era muito voltada a querer fazer isso só para poder fazer uma coisa mais ligada a situações, mais interdisciplinar [...].”

Professora Beatriz Alvarenga

Muitas características observadas nas provas foram resultados da participação, de alguns membros da equipe de elaboração, em curso ministrado no ITA.

"Logo que eu tive esse contato com o pessoal do ITA é que eu comecei a comprar mais livros americanos e franceses e ver o quê que estava acontecendo no mundo e ver porque já estava havendo uma mudança no Ensino de Física”.

Professora Beatriz Alvarenga

Logo após a implementação do vestibular único as provas apresentaram um perfil mais matematizado e teórico. Assim, exigiam conhecimentos matemáticos grandes, principalmente, para interpretação de gráficos. As questões de circuitos elétricos exigiam conhecimentos teóricos como unidades de medida, algarismos significativos, nomenclatura de componentes do circuito elétrico, entre outros. Como era uma prova de seleção, não se percebe a preocupação em avaliar habilidades ou competências dos estudantes, sendo cobrado apenas os conhecimentos teórico ou conceitual.

Com o passar dos anos, as características apresentadas pelas provas, ao longo da década de 70, foram mudando e com o passar dos anos deram lugar a outras formas de abordagem. Além disso, o número de questões, os conteúdos abordados, o grau de dificuldade das provas, também sofreram mudanças até que a prova assumisse o perfil 
atual. Segundo o professor Antônio Máximo, o fato de não se ter duas etapas de prova no vestibular dessa época contribuía para que as provas apresentassem o perfil que discutimos. "Quando se fazia essa prova, essa prova era feita com um espírito de segunda etapa hoje, quase de
segunda etapa. Quando aquela prova era preparada estava todo mundo pensando como se você fosse
fazer uma prova de segunda etapa [...] era uma prova que o pessoal fazia pensando muito mais nos
alunos de Engenharia, nos alunos de Física, nos alunos de Computação [...]. Isso aí era conseqüência
do vestibular ser único. Inclusive era uma prova mais formal do que a primeira etapa é hoje”.

Professor Antônio Máximo.

Quadro 8 - Questões 34 a 36 / vestibular 1971

\section{QUESTÕES DE Nºs. 34 A 36}

INSTRUÇÕES - As questões de nº 34, 35 e 36 estão relacionadas com o texto abaixo reproduzido. Leia com atenção cada afirmativa feita e responda de acôrdo com o seguinte esquema:

A) A afirmativa é confirmada no texto

B) A afirmativa ultrapassa o que foi dito no texto

C) A afirmativa contradiz o que foi dito no texto

O EFEITO FOTO ELÉTRICO

“O efeito foto elétrico foi descoberto em 1887 por HERTZ. Êste cientista observou que uma superfície metálica, sujeita a certas condições, emite cargas elétricas quando iluminadas por luz de comprimento de onda muito pequeno (violeta, ultra violeta). Êste fenômeno ganhou o nome de Efeito Foto Elétrico.

Uma análise mais cuidadosa das cargas originadas da superfície metálica, mostrou que elas tinham um comportamento semelhante ao dos raios catódicos e que, portanto, eram cargas negativas. Um outro cientista, J. J. Thomson, mediu a razão q/m (razão carga massa) para estas partículas e pôde verificar que o valor desta razão coincidia com o valor, já conhecido, da razão q/m das partículas dos raios catódicos. Posteriormente verificou-se que tanto as partículas do efeito foto elétrico como as dos raios catódicos eram elétrons.

Atualmente podemos fazer medidas da corrente foto elétrica com relativa facilidade já que nossos laboratórios dispõem de aparelhos bastante sensíveis , o que é essencial para o estudo dêste fenômeno. Aqui, entendemos como corrente fotoelétrica o número de elétrons emitidos por unidade de tempo na superfície metálica (chamada foto catodo) multiplicado pela carga do elétron. Uma explicação convincente do efeito foto elétrico só pode ser dada com base na teoria quântica, explicação esta que deu o prêmio Nobel, em 1921, ao Dr. Einstein.”

QUESTÃO N 34:

Por ocasião da descoberta do efeito foto elétrico já se sabia que os raios catódicos eram compostos por partículas carregadas negativamente.

QUESTÃO N 35:

Já que as partículas do efeito foto elétrico e dos raios catódicos são da mesma natureza, podemos considerar que o efeito fotoelétrico e a emissão de raios catódicos traduzem o mesmo fenômeno.

QUESTÃO N³6:

A corrente fotoelétrica deve ter pequena intensidade.

\section{6 - MUDANÇAS NA FORMA DE ABORDAGEM DE QUESTÕES DE FISICA}

Como ilustração das mudanças, destacamos nesta sessão alguns exemplos de questões apresentadas em décadas diferentes que abordam o mesmo tópico. A partir disso discutimos as mudanças quanto à contextualização, às formas de abordagem conceitual ou formal -, ao nível de conhecimento exigido e às habilidades matemáticas. 
As questões apresentadas nos quadros 9, 10 e 11 tratam, basicamente, da aplicação da Conservação da Energia, porém, com diferentes formas de abordagem. Nas duas primeiras questões é exigido raciocínio matemático e, além da compreensão de conceitos, o candidato precisa desenvolver alguns cálculos. A essa forma de abordagem chamamos "abordagem conceitual quantitativa” (FERNANDES, 2004, p.63). A última questão, entretanto, apresenta abordagem mais ligada à interpretação, exigindo o conhecimento claro dos conceitos de energia cinética, energia potencial, bem como, a relação entre esses e as grandezas velocidade e altura. A essa forma de abordagem denominamos "abordagem conceitual qualitativa” (FERNANDES, 2004, p. 62).

Quadro 9 - Questão 7 / vestibular 1975

Um garoto está descendo um grande escorregador
(tobogã) que, visto de lado, tem a aparência da
figura abaixo. Admita que o garoto partiu do
ponto $P$ com velocidade inicial nula e que o atrito
existente é desprezível. Nesse caso, a razão entre
as velocidades do garoto nos pontos $\mathrm{Q}$ e $\mathrm{R}$,
$\begin{array}{lllll}\mathrm{V} \\ \mathrm{A})\end{array}$

Quadro 10 - Questão 27 / vestibular 1995

\begin{tabular}{|c|c|c|}
\hline$\frac{\lambda}{A P}$ & 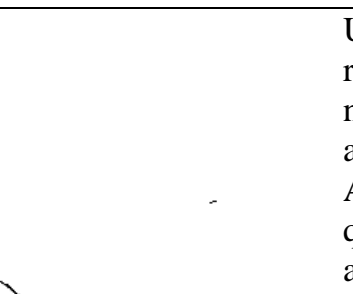 & $\begin{array}{l}\text { Um esquiador de massa } \mathrm{m}=70 \mathrm{~kg} \text { parte do } \\
\text { repouso no ponto } \mathbf{P} \text { e desce pela rampa mostrada } \\
\text { na figura. Suponha que as perdas de energia por } \\
\text { atrito são desprezíveis e considere } \mathrm{g}=10 \mathrm{~m} / \mathrm{s}^{2} \text {. } \\
\text { A energia cinética e a velocidade do esquiador } \\
\text { quando ele passa pelo ponto } \mathbf{Q} \text { que está a } 5,0 \mathrm{~m} \\
\text { abaixo do ponto } \mathbf{P} \text {, são respectivamente: }\end{array}$ \\
\hline A) $50 \mathrm{~J}$ e $15 \mathrm{~m} / \mathrm{s}$ & B) $350 \mathrm{~J}$ e $5,0 \mathrm{~m} / \mathrm{s}$ & C) $700 \mathrm{~J}$ e $10,0 \mathrm{~m} / \mathrm{s}$ \\
\hline D) $3,5 \times 10^{3} \mathrm{~J}$ e $10,0 \mathrm{~m} / \mathrm{s}$ & E) $3,5 \times 10^{3} \mathrm{~J}$ e $20,0 \mathrm{~m} / \mathrm{s}$ & \\
\hline
\end{tabular}


Quadro 11 - Questão 03 / vestibular 2004

\begin{tabular}{|c|c|c|}
\hline \multirow{2}{*}{\multicolumn{2}{|c|}{ 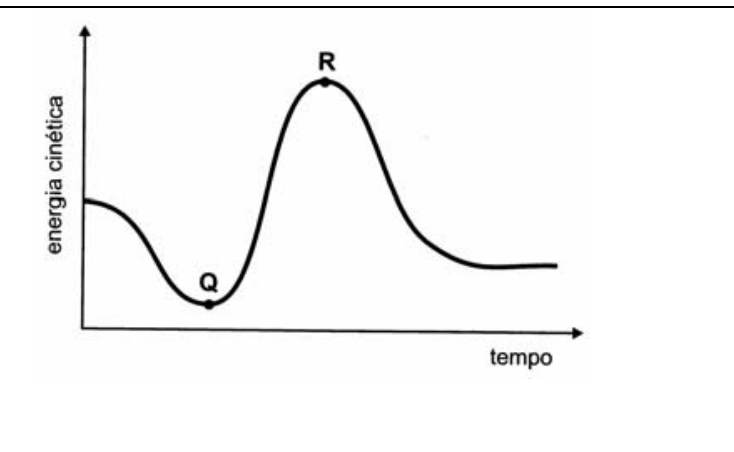 }} & $\begin{array}{l}\text { Rita está esquiando numa montanha dos Andes. A } \\
\text { energia cinética dela em função do tempo, } \\
\text { durante parte do trajeto, está representada neste } \\
\text { gráfico: } \\
\text { Os pontos Q e R, indicados nesse gráfico, } \\
\text { correspondem a dois instantes diferentes do } \\
\text { movimento de Rita. } \\
\text { Despreze todas as formas de atrito. }\end{array}$ \\
\hline & & $\begin{array}{l}\text { Com base nessas informações, é CORRETO } \\
\text { afirmar que Rita atinge }\end{array}$ \\
\hline $\begin{array}{l}\text { A ) } v \\
\text { em R. }\end{array}$ & a altura mínima & $\begin{array}{l}\text { C) velocidade máxima em Q e a altura máxima } \\
\text { em R. }\end{array}$ \\
\hline $\begin{array}{l}\text { B) ve } \\
\text { em } Q \text {. }\end{array}$ & a altura máxima & $\begin{array}{l}\text { D) velocidade máxima em } \mathrm{R} \text { e a altura mínima } \\
\text { em Q. }\end{array}$ \\
\hline
\end{tabular}

Outra coisa que podemos destacar são as formas de contextualização. A contextualização pode ser entendida como "recurso didático para problematizar a realidade vivida pelos alunos, extraí-la do seu contexto e projetá-la para a análise” (BRASIL, 2005, s.n.t.). Segundo os Parâmetros Curriculares Nacionais do Ensino Médio (PCNs), que orientam o Ensino de Física nesse nível de escolarização, a contextualização é ferramenta para associar o conteúdo a ser ensinado à experiências da vida cotidiana ou com conhecimentos adquiridos espontaneamente, de forma a tornar a aprendizagem significativa para o estudante. De acordo com Moreira (2003), a aprendizagem significativa se caracteriza pela interação entre novos conhecimentos e aqueles já existentes na estrutura cognitiva do estudante. Assim, a aprendizagem torna-se significativa quando os novos conhecimentos passam a significar algo para o aprendiz.

Percebemos que já na questão de 1975 (Quadro 9) a contextualização se apresenta de forma bem efetiva, pois a abordagem se dá a partir de uma situação diretamente ligada ao cotidiano dos alunos. As demais questões envolvem situações que não correspondem à realidade brasileira. Porém, poderíamos dizer que a forma de contextualização apresentada nos quadros 10 e 11 é uma forma de contextualização indireta, ou seja, é uma forma de representação que auxilia na compreensão do problema, porém não está diretamente ligada ao cotidiano da maioria dos alunos brasileiros.

Quanto à forma como o conteúdo é abordado, as questões apresentadas nos quadros 12, 13 e 14, que tratam da propagação de um pulso em uma corda, apresentam uma forma de abordagem do conteúdo mais voltada à avaliação do 
conhecimento e da compreensão de conceitos físicos por parte do aluno. Porém, as formas de contextualização diferem. Na primeira questão, em 1980, os pulsos são representados de forma não contextualizada, ou seja, distante do que corresponderia a uma situação real, próxima à vivência do candidato e envolvendo somente interpretação gráfica.

Quadro 12 - Questão 02 / vestibular 1980

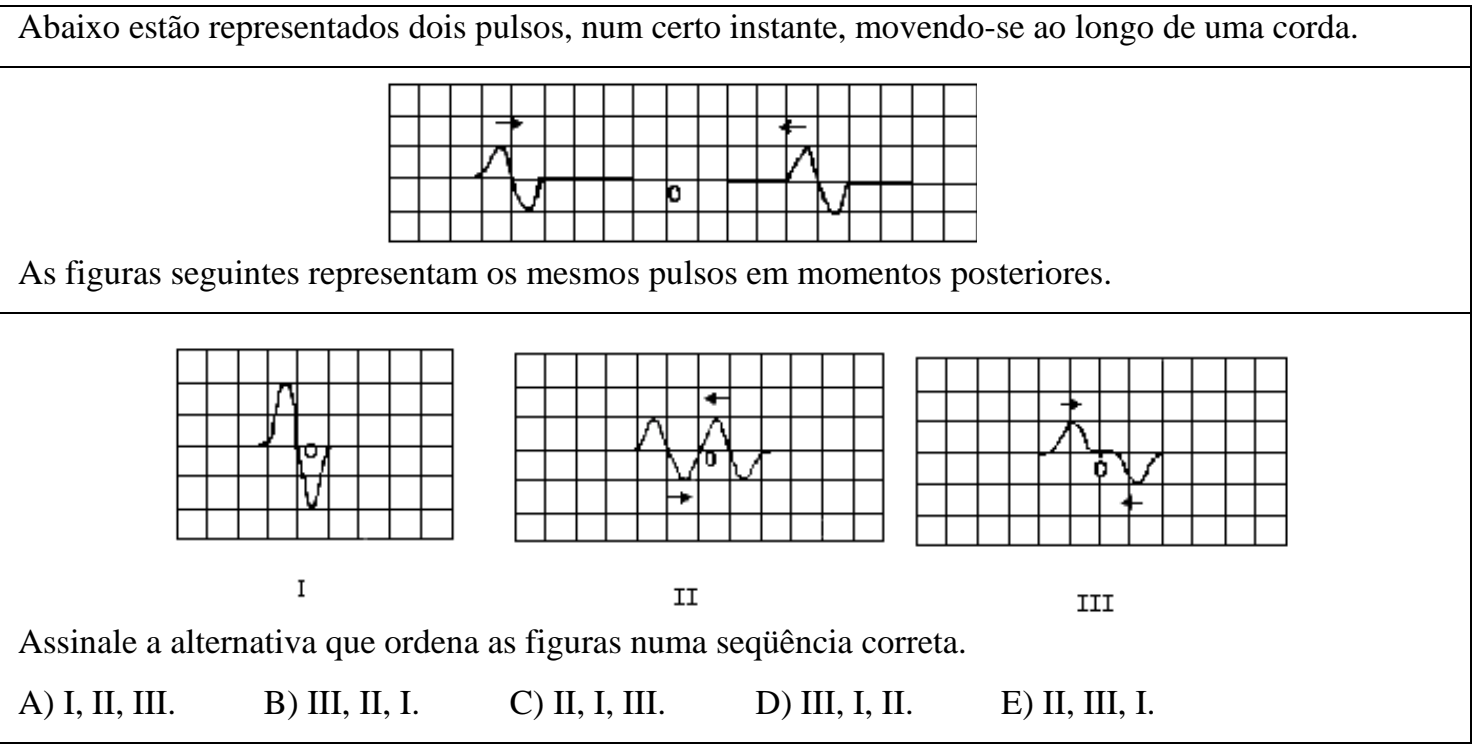

Quadro 13 - Questão 32 / vestibular 1997

Duas pessoas esticam uma corda, puxando por suas extremidades, e cada uma envia um pulso na direção da outra. Os pulsos têm o mesmo formato, mas estão invertidos como mostra a figura.

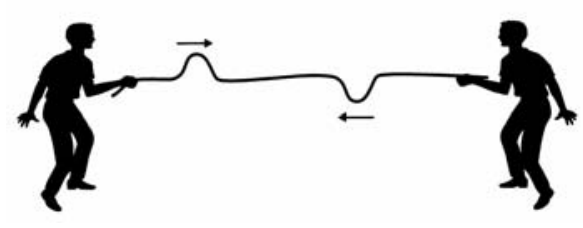

Pode-se afirmar que os pulsos

A) passarão um pelo outro, cada qual chegando à outra extremidade.

B) se destruirão, de modo que nenhum deles chegará às extremidades.

C) serão refletidos, ao se encontrarem, cada um mantendo-se no mesmo lado em que estava com relação à horizontal.

D) serão refletidos, ao se encontrarem, porém invertendo seus lados com relação à horizontal.

Em 1997 já percebemos, claramente, a presença de contextualização a partir de uma representação que pode ser facilmente observada, ou realizada pelo aluno no seu dia-a-dia. As alternativas avaliam a compreensão do estudante quanto aos fenômenos relacionados ao tópico. Talvez o fato de as alternativas não serem gráficas, dificulte a resolução da questão ou envolva um conhecimento que poderia, talvez, ter sido apenas decorado. Por último, na questão de 1999, vemos a mesma situação anterior, porém a forma de abordagem contextualizada torna-se mais efetiva devido à presença dos sujeitos (Breno e Tomás) que realizam a ação e à forma como são apresentadas as alternativas. 
Quadro 14 - Questão 08 / vestibular 1999

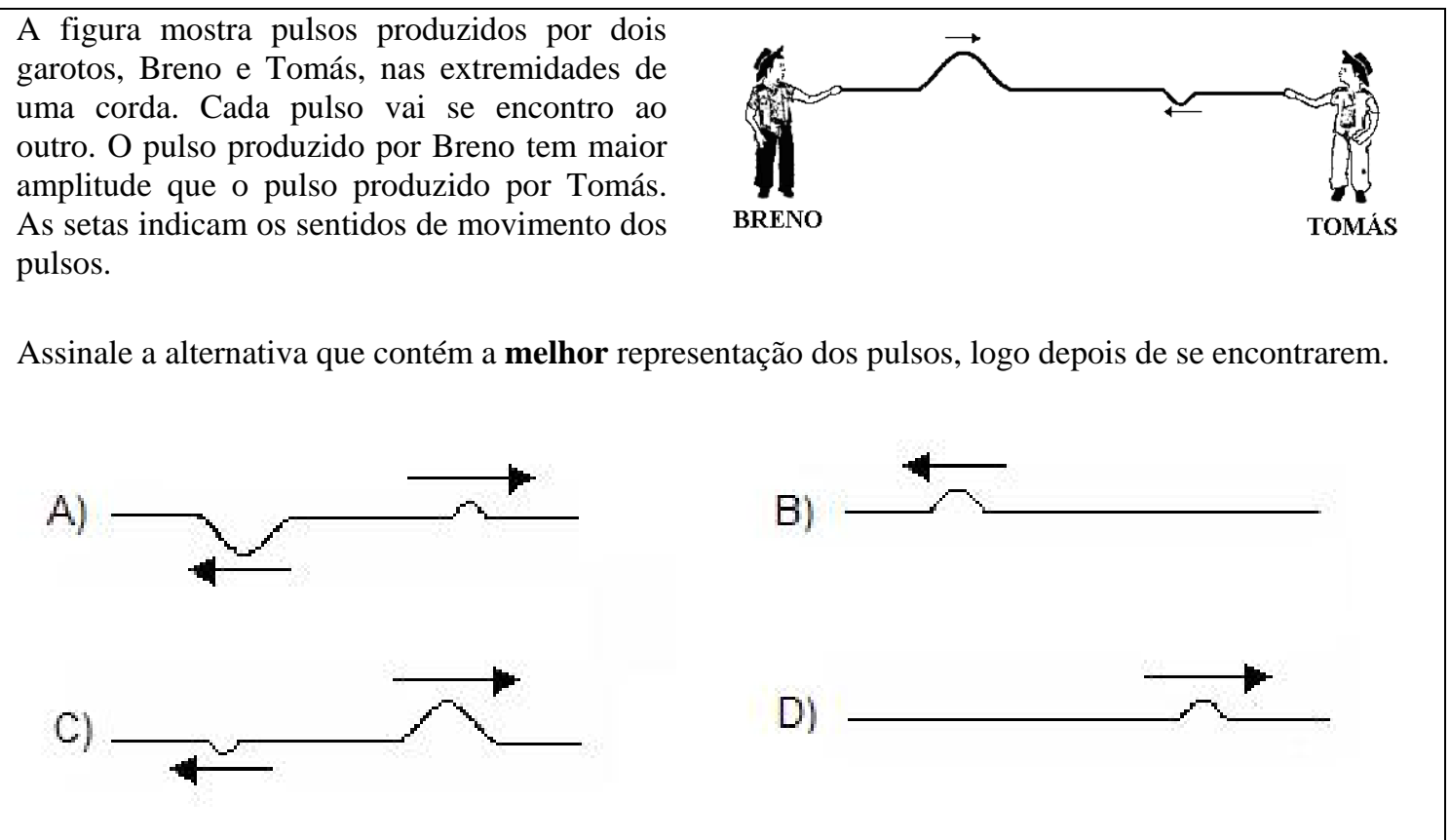

Nas questões mostradas nos quadros 15, 16 e 17 são apresentadas situações envolvendo fenômeno de refração da luz. As três questões apresentam uma abordagem conceitual qualitativa em que não são exigidos cálculos matemáticos, aplicações de equações ou relações entre grandezas. Na primeira questão, de 1974, podemos dizer que há a presença de contextualização, uma vez que uma colher mergulhada na água é uma coisa facilmente observada no dia-a-dia, porém podemos destacar alguns pontos. A situação está representada de forma errônea, pois para que tal fenômeno seja observado, é necessária uma visão feita de cima da vasilha que contém a colher, como nas questões seguintes. Assim, um observador posicionado lateralmente não poderia observar o fenômeno como representado na figura. Devido a esse engano, o aluno tem a impressão de que a colher está quebrada no sentido contrário. Além disso, a maneira como o enunciado é colocado e o fato de apresentar uma linguagem mais restrita à Física, faz com que a contextualização não seja tão efetiva quanto nas outras questões que se seguem. Além disso, apresenta um nível maior de dificuldade que as demais pelo fato de o aluno ter que perceber que a colher estar "quebrada” no sentido contrário, o que faz com que a primeira afirmativa esteja errada. A questão de 1995 apresenta uma forma de contextualização mais marcante que a primeira e envolve uma situação em que é fácil observar o fenômeno, mesmo que não seja propriamente em uma piscina. Em 2003, essa forma de contextualização se torna mais efetiva a partir de uma situação voltada à experimentação e que pode ser 
facilmente observada por qualquer aluno no seu dia-a-dia. Mais uma vez, a presença de sujeitos e a abordagem a partir de uma situação de sala de aula dão um significado à questão e contribui para a compreensão de conceitos Físicos.

Quadro 15 - Questão 42 / vestibular 1974

INSTRUÇÃO: Nas questões de 37 a 43 são feitas duas afirmativas ligadas pela palavra PORQUE. Responda:

A) Se as duas afirmativas são certas e a segunda é causa da primeira.

B) Se as duas afirmativas são certas mas a segunda não é causa da primeira.

C) Se a primeira é uma afirmativa certa e a segunda é uma afirmativa errada.

D) Se a primeira é uma afirmativa errada e a segunda é uma afirmativa certa.

E) Se a primeira e a segunda são afirmativas erradas.

QUESTÃO No 42

Quando uma colher é mergulhada obliquamente na água, sua parte imersa parece quebrada para baixo (veja figura ao lado)

PORQUE

A velocidade da luz na água é menor do que no ar e conseqüentemente seu índice de refração é superior a 1.

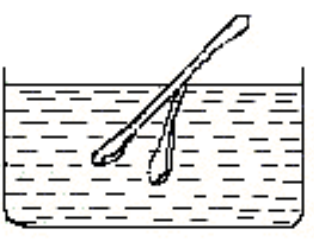

Quadro 16 - Questão 33 / vestibular 1995

O empregado de um clube está varrendo o fundo da piscina com uma vassoura que tem um longo cabo de alumínio. Ele percebe que o cabo de alumínio parece entortar-se ao entrar na água, como mostra a figura.

Isso ocorre porque

A) a luz do sol, refletida na superfície da água, interfere com a luz do sol refletida pela parte da vassoura imersa na água.

B) a luz do sol, refletida pela parte da vassoura imersa na água, sofre reflexão parcial na superfície de separação água-ar.

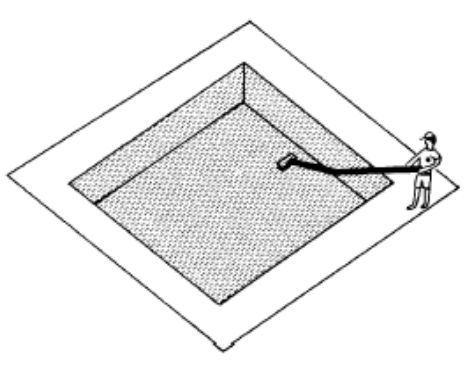

C) a luz do sol, refletida pela parte da vassoura imersa na água, sofre reflexão total na superfície de separação água-ar.

D) a luz do sol, refletida pela parte da vassoura imersa na água, sofre refração ao passar pela superfície de separação água-ar.

E) o cabo de alumínio sofre uma dilatação na água, devido à diferença de temperatura entre a água e o ar.

Quadro 17 - Questão 09 / vestibular 2003

Um professor pediu a seus alunos que explicassem por que um lápis, dentro de um copo com água, parece estar quebrado, como mostrado na figura.

Bruno respondeu: "Isso ocorre, porque a velocidade da luz na água é menor que a velocidade da luz no ar”.

Tomás explicou: "Esse fenômeno está relacionado com a alteração da freqüência da luz quando esta muda de meio”. Considerando-se essas duas respostas, é CORRETO afirmar que
A) nenhuma das duas está certa.
B) apenas a de Tomás está certa.
C) apenas a de Bruno está certa.
D) as duas estão certas.

Nos Quadros 18, 19, 20 e 21, apresentamos questões que tratam do lançamento vertical de um objeto. Na primeira questão, referente à prova de 1977, percebemos que a abordagem do conteúdo se apresenta de forma não contextualizada. Assim, apesar de envolver o conhecimento de conceitos, a solução é mais quantitativa, o 
candidato deve reconhecer a equação matemática que melhor represente a situação do problema.

Quadro 18 - Questões 27 a 29 / vestibular 1977

INSTRUÇÕES: As questões de 27 a 29 referem-se ao enunciado:

Uma pedra, de massa $\mathrm{m}$, é lançada horizontalmente, com velocidade $\mathrm{v}_{\mathrm{o}}$, a uma altura $\underline{\mathrm{h}}$ do chão (despreze a resistência do ar).

QUESTÃO N²7

A energia cinética da pedra, no instante do lançamento, é
A) $\mathrm{mv}_{\mathrm{o}}{ }^{2}$
B) $m v_{0}$
C) $\frac{1}{2} m v_{0}^{2}$
D) $m\left(\frac{v_{o}}{2}\right)^{2}$
E) zero

QUESTÃO N 28

Considere a energia potencial, no chão, igual a zero. A energia cinética da pedra, a uma altura h/4, é
A) $\mathrm{mv}_{\mathrm{o}}+\frac{3}{4} \mathrm{mgh}$
B) $\frac{3}{4} \mathrm{mgh}$
C) $\frac{m v_{0}^{2}}{2}+\frac{m g h}{4}$
D) $\frac{\mathrm{mv}_{\mathrm{o}}^{2}}{2}+\frac{3}{4} \mathrm{mgh}$
E) $\frac{1}{2} m v_{o}^{2}+\frac{3}{4} \mathrm{mgh}$

QUESTÃO N²9

A quantidade de movimento da pedra, no instante de lançamento, é
A) $m g \sqrt{2 g h}$
B) $2 m v_{0}$
C) $\frac{1}{2} \mathrm{mv}_{\mathrm{o}}{ }^{2}$
D) zero
E) $m v_{o}$

Quadro 19 - Questão 11 / vestibular 1984

Uma pedra é lançada verticalmente, de baixo para cima, com velocidade inicial $+2,0 \mathrm{~m} / \mathrm{s}$.

O gráfico que melhor representa a velocidade da pedra em função do tempo é
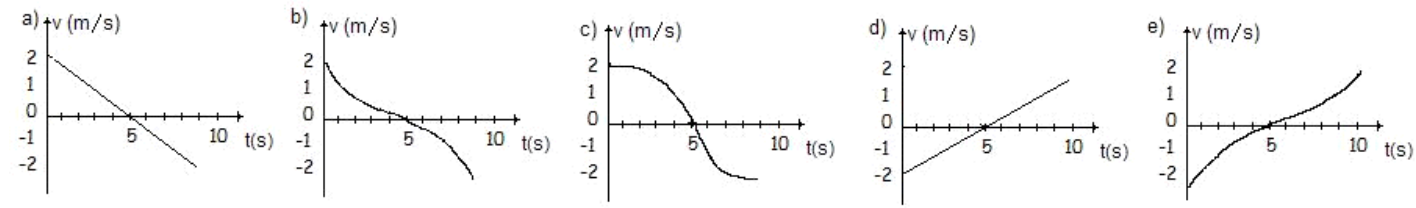

Quadro 20 - Questão 21 / vestibular 1995

Uma criança arremessa uma bola, verticalmente, para cima. Desprezando-se a resistência do ar, o gráfico que representa corretamente a velocidade $\mathbf{v}$ da bola, em função do tempo $\mathbf{t}$, é
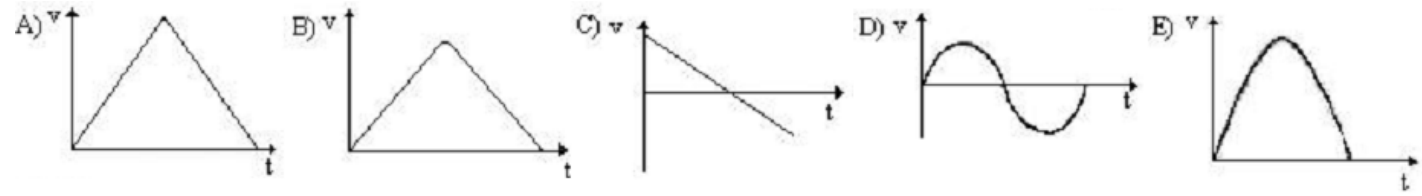

Na década seguinte, em 1984, a abordagem ainda é conceitual, porém o tratamento dado à questão não é tão quantitativo quanto na questão anterior. A essa forma de abordagem chamamos semi-quantitativa (FERNANDES, 2004, p.62), que se trata de uma abordagem de conteúdo que exige do estudante, além do conhecimento e compreensão de conceitos físicos referentes ao conteúdo, também a relação entre grandezas e/ou interpretação de equações e gráficos simples. A questão de 1995 é abordada da mesma forma que a anterior, porém, estabelece-se uma pequena diferença quando diz-se que uma criança lança a pedra, o que nos parece uma tentativa de criar 
um contexto tornando a questão mais interessante para o candidato. Por último, na questão do ano de 2004, que também apresenta a mesma abordagem conceitual e semi-quantitativa, percebemos uma contextualização ainda maior.

Quadro 21 - Questão 01 / vestibular 2004

Da janela de seu apartamento, Marina lança uma bola verticalmente para cima, como mostrado na figura.

Despreze a resistência do ar.

Assinale a alternativa cujo gráfico melhor representa a velocidade da bola em função do tempo, a partir do instante em que ela foi lançada.
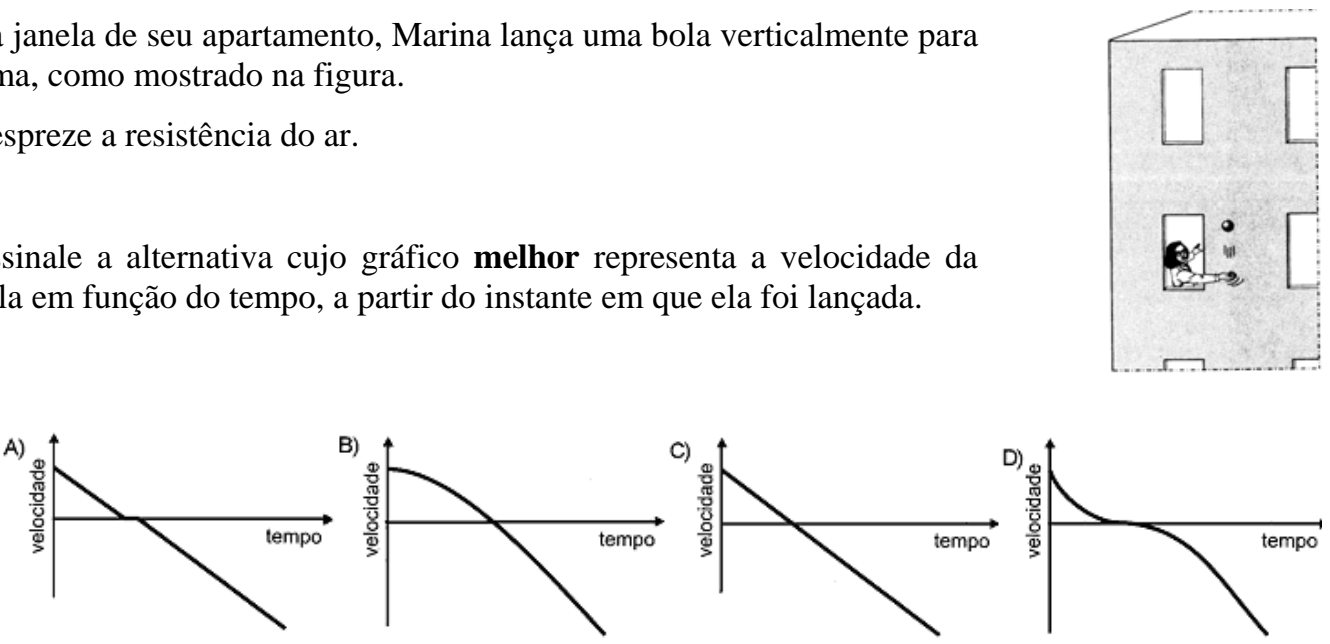

Podemos perceber nos exemplos apresentados algumas mudanças nas formas de abordagem que, na maioria das vezes, começa de forma mais quantitativa e passa a uma abordagem mais conceitual e semi-quantitativa ou conceitual e qualitativa. Essas mudanças são percebidas nas provas como um todo e mostram que, com o passar dos anos essas foram valorizando mais o raciocínio, interpretação e o conhecimento de conceitos físicos por parte dos candidatos.

A partir da promulgação da nova Lei de Diretrizes e Bases da Educação Nacional em 1996 (LDB) e com a implementação dos PCNs em 1999, das Orientações Complementares aos PCNs em 2002 (PCN+) e das últimas discussões a respeito de tais orientações em 2005 - Parâmetros Curriculares em Debate - o ensino de Física, na escola média, tem passado por algumas tentativas de mudanças (FERNANDES, 2004). Um dos focos de tais mudanças é promover um ensino mais significativo para o estudante, preocupado com a compreensão de conceitos físicos em detrimento à valorização de fórmulas matemáticas e conhecimentos decorados. Porém, analisando as questões de Física das provas do vestibular da UFMG ao longo das décadas, podemos perceber que tais mudanças ocorreram antes mesmo da promulgação da LDB e implementação dos PCNs. Assim, é possível encontrar questões com abordagens contextualizadas antes mesmo da proposta de reformulação do Ensino Médio. 
“Os PCNs colocaram no papel aquilo que a gente já tinha na cabeça, então não foi muita novidade”. Professor Árjuna.

\section{3 - CONCLUSÃO}

Em resumo, podemos dizer que as provas de Física do vestibular da UFMG passaram por alguns momentos bem marcantes. O primeiro deles com a implementação do vestibular único, em que a prova era feita em uma única etapa e, dessa forma, tentando atender àqueles alunos que pretendiam ingressar em cursos da área de exatas, o perfil apresentado pelas questões tinha um enfoque conceitual, porém quantitativo. Em algumas questões a exigência da compreensão ou do conhecimento de conceitos era pouco significativa frente aos cálculos exigidos. Posteriormente, com a implementação da segunda etapa em 1978, as provas da primeira etapa puderam avaliar conhecimentos mais básicos e, assim, passaram a apresentar abordagens mais conceituais qualitativas e semi-quantitativas. Desse ano até o final da década de 80, as questões assumem um perfil definido e, mesmo não se falando em Reforma Educacional e PCNs, abordagens valorizando mais a compreensão de conceitos, menos matematizadas e contextualizadas já estavam presentes, o que se devia à própria postura assumida pela equipe de elaboração das provas de Física.

\section{4 - REFERÊNCIAS BIBLIOGRÁFICAS}

BRASIL. Ministério da Educação, Secretaria de Educação Média e Tecnológica. Diretrizes Curriculares Nacionais para o Ensino Médio. Brasília, 1998. 65p. . Parâmetros Curriculares Nacionais ${ }^{6}$ : Ensino Médio. Brasília, 1999. 360p.

- Ciências da Natureza, Matemática e suas Tecnologias: Orientações Educacionais Complementares aos Parâmetros Curriculares Nacionais. Brasília: 2002. 144p.

Parâmetros Curriculares Nacionais em Debate (PCN 2005).

Ensino Médio. Brasília: 2005 (s.n.t.)

UNIVERSIDADE FEDERAL DE MINAS GERAIS. Manual do candidato 2005. Belo Horizonte, MG.

\footnotetext{
${ }^{6}$ Este documento compreende, além das orientações para o Ensino Médio, a LDB (pp.39-58) e as DCNEM (pp.59-118).
} 
DALBEN, A.I.L.F. O perfil técnico-pedagógico das provas do vestibular/UFMG. In: Física no vestibular: provas e comentários. 2002. CAMPOS, A. [et.al] Belo Horizonte, 1999. Ed. UFMG.49p.

FERNANDES, Simone A. O Ensino de Física no novo Ensino Médio e os Processos Seletivos para o Ensino Superior, 2004. 147p. (Dissertação de Mestrado. Universidade Federal de Minas Gerais)

NETO, P.E.M. Vestibular e exame de ordem: uma análise crítica. Ensaio. n.8, pp. 317- 322, jul./set. 1995.

PSSC. Física. Physical Science Study Committee. Tradução por Heitor G. de Souza [et al.].São Paulo; EDART, 1963.

VASCONCELLOS, Celso. S. Superação da lógica classificatória e excludente da avaliação: do “é proibido reprovar” ao é preciso garantir a aprendizagem. São Paulo: Libertad ; 1998. - (Coleção Cadernos Pedagógicos do Libertad ; v. 5).

VASCONCELLOS, Celso. S. (Des) alienação do cotidiano escolar sobre as relações um tanto obscuras e tenebrosas entre o vestibular e os cavaleiros do apocalipse pedagógico (o conteúdo preestabelecido sem sentido, o professor falando o tempo todo e a avaliação classificatória). Revista de Educação AEC. n.117, pp. 85-102, 2000 